\section{Learning about Urbanism and Life in Brazil}

Aaron Brownwood

Karlo Felix

Leah Price

BSCRP students, Cal Poly
Aron Nussbaum

LA Arch student, Cal Poly

In 2005 a total of six Cal Poly students participated in the CRP department's exchange program with the School of Architecture and Urbanism at the Federal University of Rio de Janeiro. This was the largest contingent of Cal Poly students in Brazil over a single academic year and also included students from the Landscape Architecture Department, what proves the success of this exchange program. CRP students Aaron, Karlo and Leah, and LA student Aron Nussbaum share their thoughts about academic and life experiences in Brazil.

\section{Aaron Brownwood's thoughts}

Arriving in Brazil was great. Ricardo, Carol, and Leticia (local students who had participated in the exchange with CRP) were waiting at the airport and took us directly to the hotel where we were staying. Ricardo's mother helped us find a nice apartment in Copacabana and also gave us daily language lessons which were great.

I went alone for my first day of school and with only a little information regarding where my class was. I had been in Brazil for less than two weeks and my Portuguese was horrible. It took me nearly twenty minutes to find someone who spoke some English and then that person had to find another professor who was able to direct me to my class.

Surprisingly classes were not as difficult as I imagined them to be. I learned a lot of language when working in teams since no one spoke much English. Of course, at (many) times I was lost but personally speaking, the main messages were transmitted and understood. I enjoyed both my classes. Unfortunately, I did not attend much of the watercolor painting class because of conflicting events happening at the university. For example I missed two classes because I went on a two-week trip to participate in the conference of Latin American architecture students in Fortaleza, in the northeast of Brazil. It was a sixty hour bus ride with about 35 students from Faculdade de Arquitetura e Urbanismo and I got to know ALL of them very well and they really took me in as one of their own.

The urbanismo class I took was not very educational for me but I enjoyed the people in the class and working with my group. I wouldn't say that this class was bad but it seemed to have very little direction; the professor did not provide us guidelines to work with. She recommended readings and gave examples of types of urban form but gave no restrictions on our group projects, which was confusing. I think the professor should have taught us the current land use laws in Rio and Brazil and how to plan within those regulations.
Just planning an area with no restraints doesn't really teach much about planning. Maybe one can learn about spatial relationships and how buildings relate to the street, etc. but everyone's final project seemed so different and arbitrary, as if we were all in different classes.

For the next students who come I would recommend more language lessons even if he/she knows Spanish. Its not much help when it comes down to it. I think that the way FAU operates can be a bit hard for us to understand but I also think students should be somewhat prepared for that and the conditions in a developing country. For example, the lack of toilet paper, soap, and hand towels in the school's bathrooms. It was a major shock to get accustomed to FAU. This is not that they operate incorrectly, it's just so different than anything we deal with. Finding classes can be difficult because the building is huge (there are almost 1,500 students in the architecture school!) and classrooms are hard to find. Bottom line: students should understand how FAU operates and how to get by upon arrival.

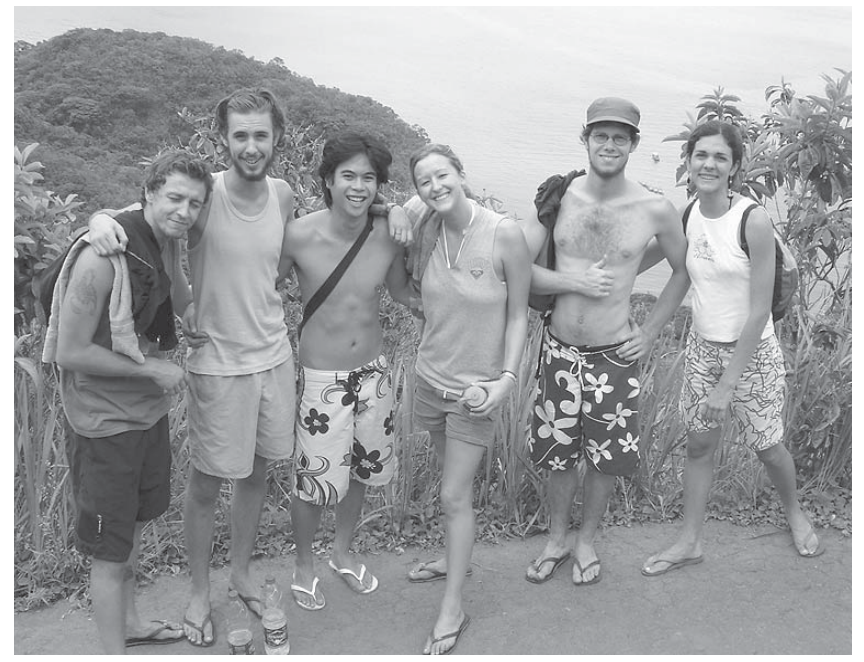

Figure 1. Aaron, Karlo and Leah (second, third and fourth from the left) and friends hiking in Ilha Grande, Brazil. 
One of the greatest things about the Brazilian culture is the friendliness and openness of the people. Students were so great to us and the professor was equally as welcoming. It took a couple of weeks but I began to know each of the students in our class to some degree. My group understood that I had poor language skills yet still tried to talk with me and ask me questions. They really wanted to learn from me which surprised me. I would recommend others to come to Brazil and see the great country that it is.

\section{Karlo Felix's thoughts}

Picture postcards do not do the "Cidade Marvilhosa” justice. Rio de Janeiro stunningly spills between its forest covered peaks and coastlines. The seductive curves of its mountains are mirrored in the sensuous arcs of its beaches. Bustling like the throbbing beat of the samba, Rio is a city that never ceases to amaze. Along with three other CAED students (Aaron Brownwood, Santiago Garcia, and Leah Price), I studied at the Faculty of Architecture and Urbanism of the Federal University of Rio de Janeiro. It is one of the most prestigious schools in Latin America; while there I had the opportunity to study with the future environmental designer of Brazil. During my almost 6 month stay in Rio, I was able to fully immerse myself in Brazilian culture and also meet other students from around the world. I came away with a greater knowledge in international planning, a new awareness for cultural peculiarities, and a love for Rio de Janeiro.

Located at Ilha do Fundão, a 1,200-acre man-made island created exclusively for the university, the university became the subject of my studies. Fundão was created in the 1950's by filling in nine islands in Guanabara Bay in the city's

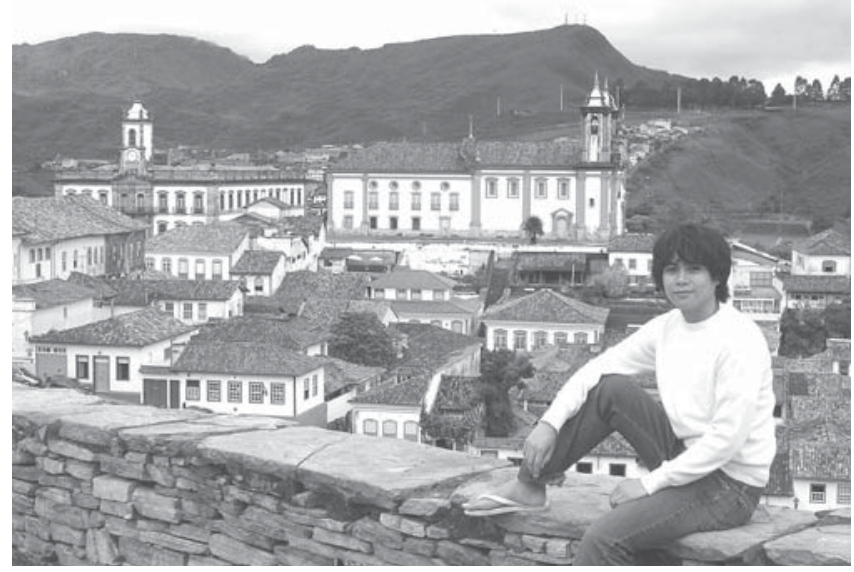

Figure 2. Karlo in Ouro Preto colonial historic town.
North Zone. The plan for the island was chosen through a competition and was won by the famous Brazilian architect, Jorge Machado Moreira. His plan called for providing adequate academic space for the premier teaching and research institution of Brazil, then called the University of Brazil. It also called for wide avenues and expansive green spaces. The new academic structures were built in the modernist style and became the new landscape for the island. Unfortunately, his plan was not fully realized and a majority of the campus remains unfinished to this day.

In my urbanism class I was placed in a group with three other Brazilian students. Through collaboration and compromise, our final design proposed a "new" model for the Brazilian university. Rather than being solely an academic district, we proposed integrating more of the city into the island. Shops, restaurants, bars, hotels, offices, apartments, theatres, and other services would make their place among laboratories, classrooms, and studios to create a more vibrant community. The plan itself called for a continuation of modernistic academic buildings, superimposed onto a traditional street grid and connected with large tree-lined axes. Although some items in our proposal ended up needing further exploration, our project became an interesting exercise in integrating ideas from both Brazil and California.

My other studies focused on urbanism and the environment. While many students at the school seemed to dislike the political nature of the subject matter, I found the coursework both interesting and engaging. The class focused on the evolution of Rio's built form, and how those forms have affected its natural environment, its economy, and its people.

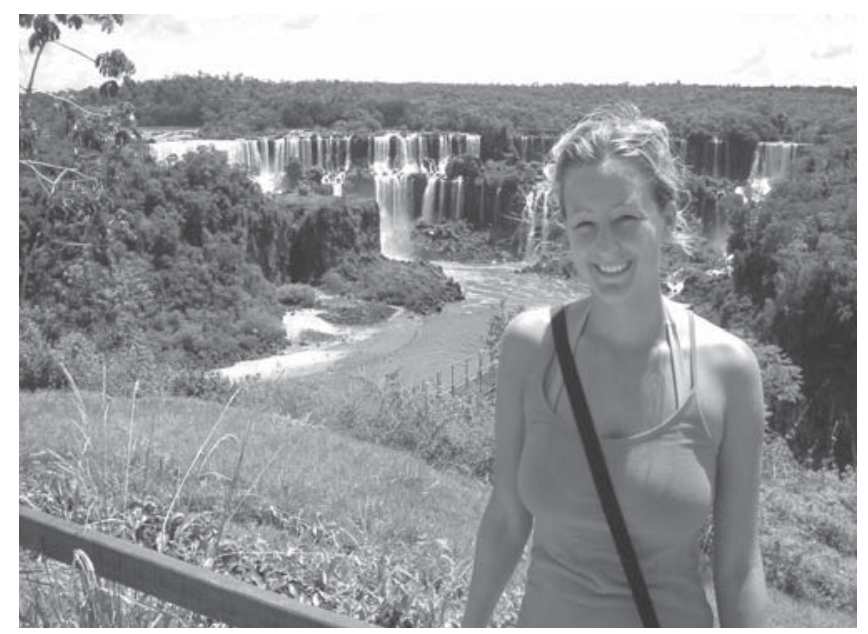

Figure 3. Leah at the Iguazu Falls. 
With CRP's focus on environmentally conscious decisionmaking, it was interesting to partake in a class and see many of the same ideas applied in different ways. The class also proved to be challenging as Brazil has very different agencies charged with environmental review. Learning the structure and responsibilities of these agencies provided me with a different perspective on our own environmental practices here in California.

But the beauty of Rio de Janeiro kept me from focusing entirely on academics. With spectacular beaches, beautiful mountains, an endless nightlife and friendly citizens, Rio provided enough distractions. Cariocas, as citizens of Rio de Janeiro are affectionately called, are a beautiful and amazingly accepting people. To them arriving fashionably late is almost a rule, ever-changing plans are a norm, and chance encounters while waiting in Brazil's many long lines become social events. Dramatic soap operas and football are always spoken of with flailing arms, wide eyes, and profound passion. But despite the discussions of distaste over the latest governmental corruption scandal or the failure of the latest civic project, Cariocas are rightfully proud of their city and proud of their country.

My senses have been seduced by the splendor of Rio's scenic surroundings. The Carioca spirit has captured my heart. Brazil has been one of the greatest experiences in my life. The experience was a challenge that I am glad I undertook. Aside from learning to work in another language,
I was provided insight into how Brazilians think about their surroundings and therefore organize their urban form. I know that the Cariocas have left a definite impression on the way I think; not only about the built environment, but about life as well. I hope that I was able to reciprocate the act and leave a positive impression upon all the people I have encountered in Rio.

\section{Leah Price's thoughts}

Where should a student travel if that student desires adventure, the experience of another culture, and a different perspective on planning, design and environmental protection while not incurring additional student loans? For me, this question was answered after a late night conversation with Sierra Russel in CRP's Computer Lab. This is how I ended up in Rio de Janeiro Brazil with three friends from Cal Poly for five and a half months of study, travel and cultural education.

The city of Rio de Janeiro can only be summed up with one word- amazing. It is not possible to understand its true meaning unless you have experienced the city yourself. From a planner's perspective Rio has the typical problems of a large city; odors, traffic, crime, air pollution and more. But the largest and most complex problem is the irregular development that occurs on the hillsides throughout the city, favelas. These shantytowns are a blatant display of the social inequality that exists within the city and the enormous social, economical and environmental problems Rio faces because of it. These issues and other obvious disregards for laws and regulation kept me constantly fascinated while living in Rio.
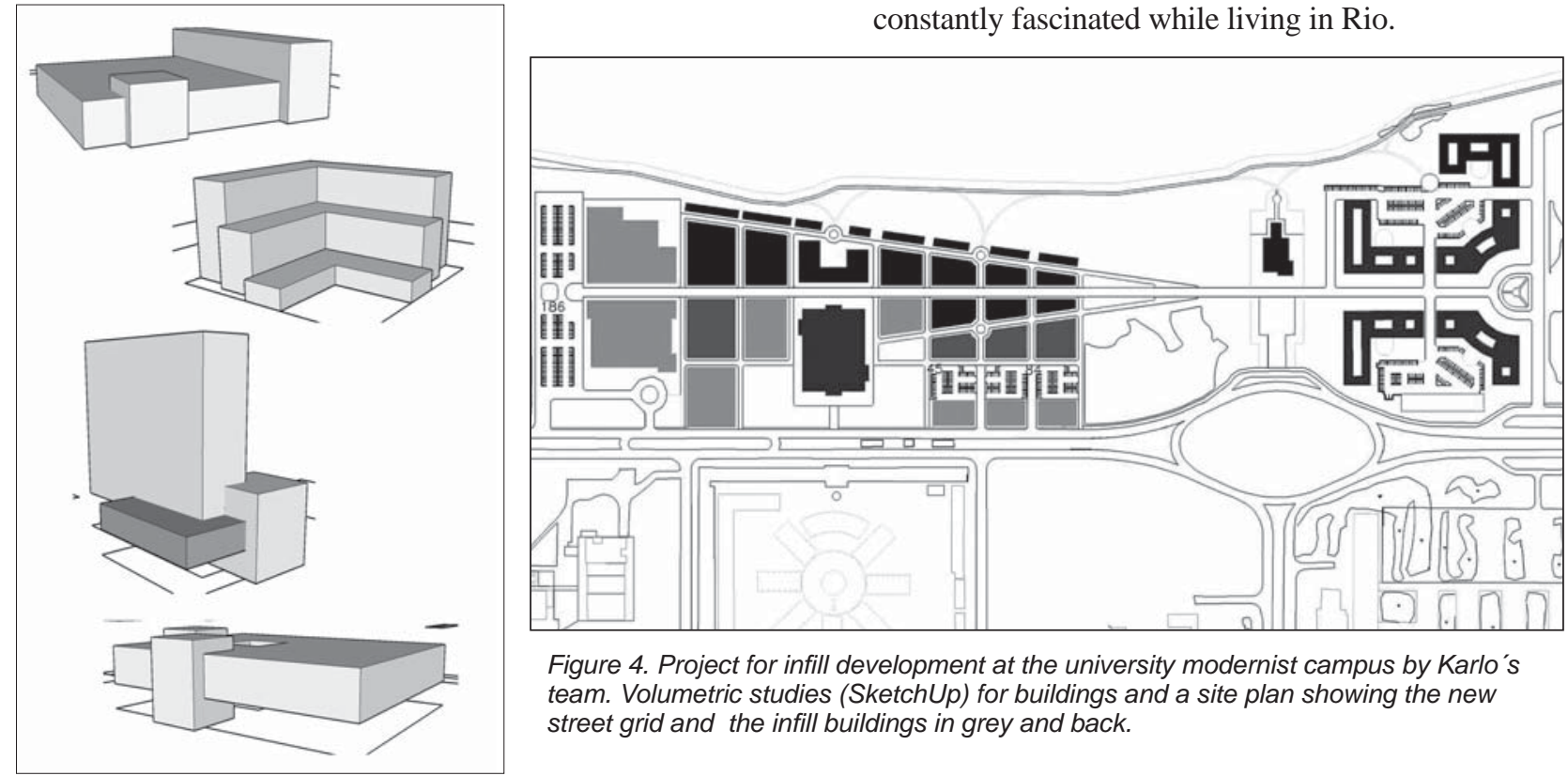

Figure 4. Project for infill development at the university modernist campus by Karlo's team. Volumetric studies (SketchUp) for buildings and a site plan showing the new street grid and the infill buildings in grey and back. 
However, not all of my learning experience was a result of negativity. I thoroughly enjoyed the carioca (natives of Rio) attitude about life and the sincerity of almost everyone we encountered. The city itself was a prime example of proximity; high-density development, mixed uses, culture, character and vibrancy existed almost everywhere. Buses were packed with people of all demographic classes, the sidewalks were always full of people, and in the evening it was nearly impossible to walk. The metro station dropped cariocas off at plazas where vendors waited to sell various fatty foods, and old men played chess in the evening. Rio has an energy and life our cities so often lack in the United States.

Nightlife in the city was the best; whether it was a chill bar in Leblon, live music or a street party in Lapa, or various nightclubs throughout the city, Rio has a scene for everyone. Or, if you like, just hang out; or more realistically, conclude your evening at a waterfront kiosk with one last drink and enjoy the characters you encounter at 4 am on the beach. The night will come to an end when you sense the sky lighten and early morning joggers start to appear in spandex and other outrageous attire. If you're lucky, your day will begin with a recovery trip to Ipanema beach, where one's biggest concern is to find a vacant patch of sand among the crowd of beautiful people and locate the açai (Amazon fruit) guy before your favorite icicle is gone.

When we arrived in August at the University Federal do Rio de Janeiro, my colleagues from CRP Aaron, Karlo, Santiago and I had been prepared as to the conditions of the facilities on campus, along with the modern design style. The facilities and organization within the University were not what we

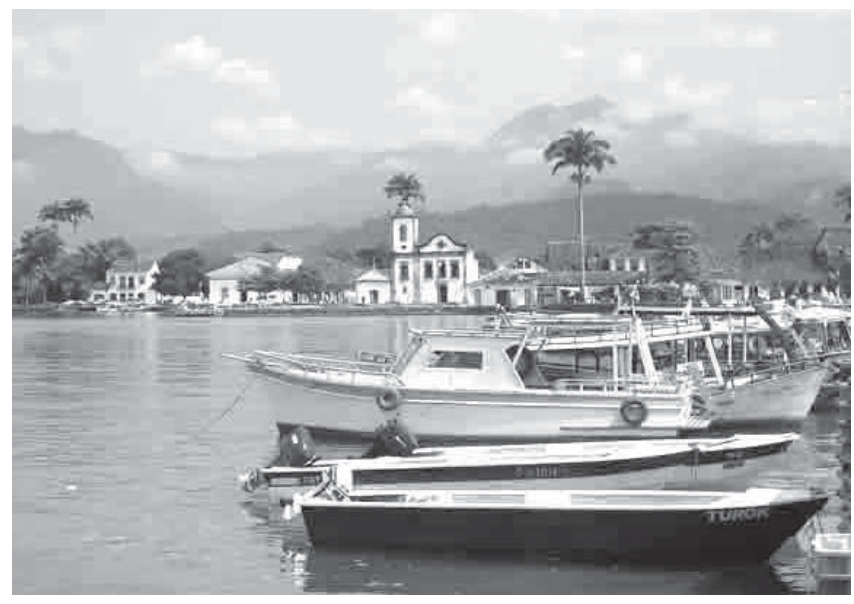

Figure 5. The historic colonial town of Paraty, on the coast south of Rio. (photo by Leah Price) were used to at Cal Poly, yet we were able to enroll and meet some of our classmates with ease. Our classes included an Urbanism Lab and an Environmental Planning class. In addition, we took a Portuguese class at another college, Faculdade de Letras, just across the street.

Although we knew little Portuguese upon arrival, we were still able to gain an international perspective on urban design. It was very interesting to see how my group members dealt with social, environmental, and economic issues in the design of the university campus that is located at the island of Fundão. The environmental class gave us a brief history of the evolution of Rio, its environmental policies and current problems, and sustainability concepts. The class included discussions and analysis of environmental conditions throughout the city and the campus island. It was very interesting to experience familiar concepts applied to a different culture, society, and nature. Brazilian ideas and thoughts gave me insight and a new perspective for regarding how they prioritize environmental problems and sustainability concepts.

Brazil was my first real experience outside the United States, and almost everyone told me this experience would be life changing. I have to agree that it was just that, even though the difference came about through a different means than I expected. Together, my academic and personal experiences were very educational. I was able to step from a perspective I have always had into another where concepts and ideals I had been taught as import took a back seat to basic necessity such as health and safety. Rio knows no bounds, it is an amazing city in a country where culture and character is everywhere. The people I met and the memories I have are irreplaceable

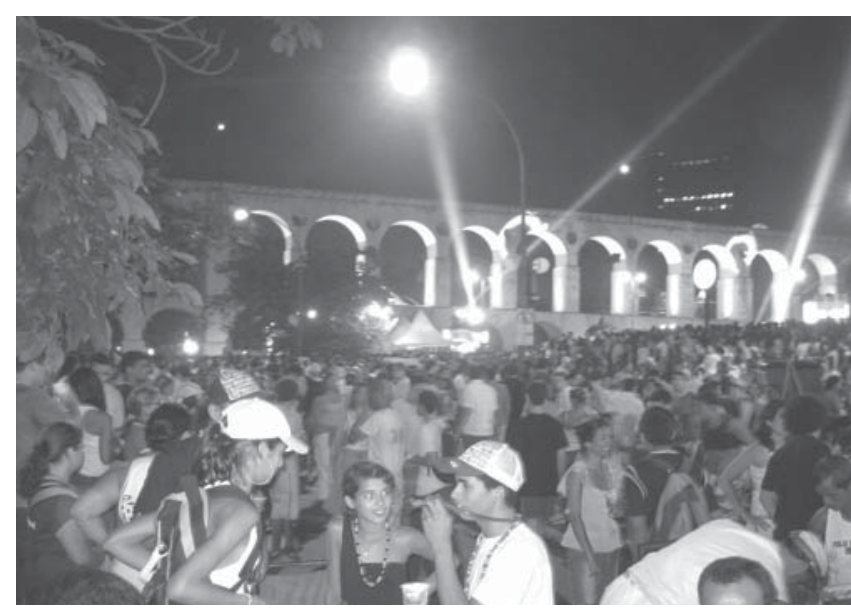

Figure 8. Partying on a Saturday night at Lapa, Rio de Janeiro. A revitalized area with numerous bars, art galleries, and night clubs that holds several public events in the year. (photo by Karlo Felix) 
and the experience made for a perfect conclusion to my college education.

\section{Aron Nussbaum: "Vida no Brasil"}

...Sunday afternoon, sun at full staff, the heat fills every breath, fans blast on my bare skin, windows wide open. Working fastidiously on my makeshift sawhorse desk. Eyes are constantly drawn away from my paper to the window, the view of the city below my high-rise apartment, the view of the mountains and jungle, the famous Cristo Redentor (Christ the Redeemer) statue, and the music of drum and dance echoing through the blocks. Yes. It was Sunday and the weather was beautiful, another unofficial holiday in Rio de Janeiro. Tossing my work aside, I grab my Havaianas (Brazilian flip-flops), my bike and descend down the service elevator heading towards the music. I am quickly at the street level of Botafogo, a diverse neighborhood at the doorstep of Pão de Açucar (Sugar Loaf) mountain offering views of the entire city set amongst its extreme topography of mountains, bays, lakes, and forests with in a dense urban fabric of apartment high rises.

I continue to descend my rusty bike towards the city with my ears tuned to the sounds of the drums, remembering my golden rule, maneuvering through the city with the intent of staying on my bike and arriving at my predetermined destination alive. In the dense urban jungle of Rio de Janeiro maneuvering through speeding taxis and motorcycles and the onslaught of pedestrians, delivery bikes, parked cars, dogs, trees, magazine stands, fruit carts, policia, patio seating, street merchants, and very large buses, riding a bike through the city can add up to quite an adventure. And if it's past 10 at night, not that I would consider riding my bike, cars are not required to stop at red lights... an effective way that developing countries manage their security issues.

I finally make it through the multiple intersections into relatively calm streets and find my destination. Groups of people have gathered together each holding a different drum and are marching through the street creating a rhythm that can be heard for miles or rather, kilometers. Kids follow along with their bicycles and soccer balls, women and children dance, shopkeepers stand and watch in front of their shops, the city stops to listen, dance, talk, and walk together. I follow with my bicycle passing by corner cafes and juice bars open to the street with their stools and tables set out on the sidewalks, we pass by the local hardware store, the automechanic, the hair salon, the butcher shop, the bakery, the little bars. Each city block we pass under the shade of trees and the sounds of birds, we pass by the residential towers lining the street with the door men out front watching the crowd, we pass by taxi drivers pulled over taking a cigarette break, we pass by a farmers market selling fresh fruits, flowers, spices, fish, and meat, we pass a cart selling fresh coconut water, another cart selling batteries and can openers, we pass by a couple in bikinis and Speedos on their way to the beach, we pass by a man selling old records and books, we pass by a kid passing out flyers for a live show, we pass a magazine and newsstand, we pass our neighborhood as we parade down the street to the beat of the drums.

We march our way into the central plaza. An urban gathering on a Sunday afternoon. We sit, laugh, hug, kiss, and rejoice the brilliant sun, the beat of our hearts, and the rhythm that keeps the spirit of Rio de Janeiro dancing and celebrating its eternal ecstasy.

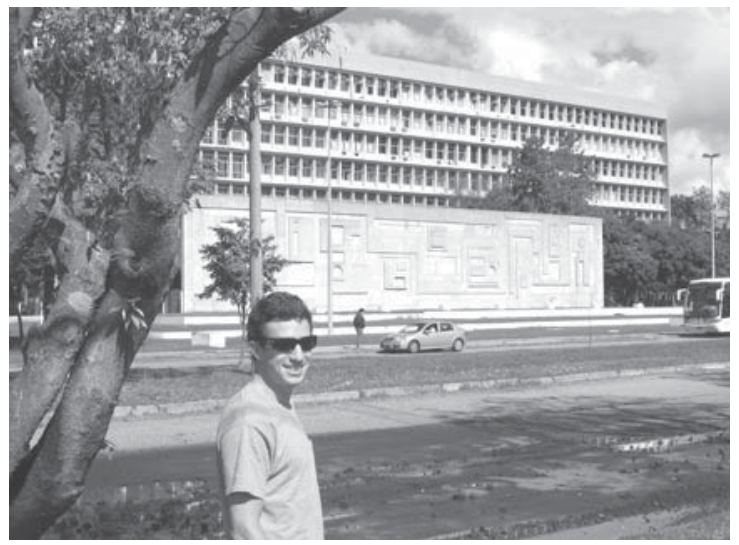

Figure 7. Aron in front of the School of Architecture and Urbanism, Federal University of Rio de Janeiro. (photo by V. del Rio)

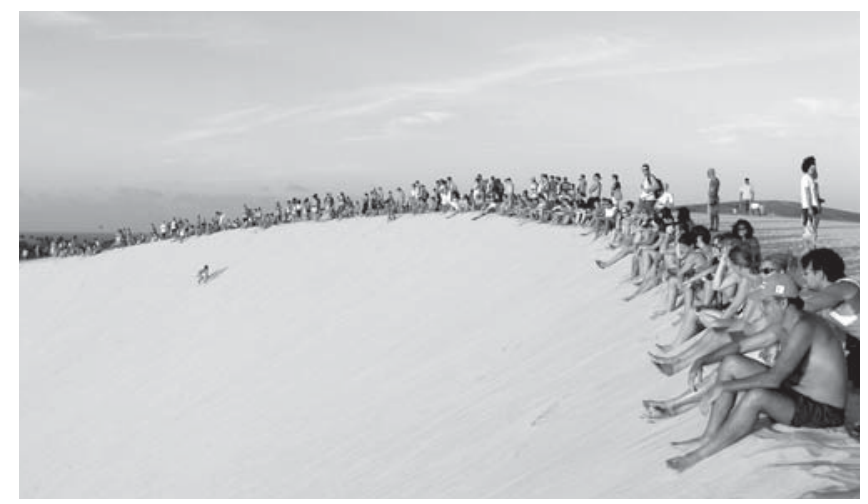

Figure 8. Sunset in Jericoacoara Ceará (Northeast Brazil), overlooking the Atlantic from the top of the sand dunes. (photo by $A$. Nussbaum) 